\title{
Understanding Dry Powder Inhalers: Key Technical and Patient Preference Attributes
}

\author{
Mark L. Levy (D) - Will Carroll · José L. Izquierdo Alonso • \\ Claus Keller · Federico Lavorini · Lauri Lehtimäki
}

Received: July 22, 2019 / Published online: September 2, 2019

(C) The Author(s) 2019

\section{ABSTRACT}

Inhalable medications for patients with asthma and chronic obstructive pulmonary disease (COPD) can be confusing even for health care professionals because of the multitude of available devices each with different operating principles. Dry powder inhalers (DPI) are a

Enhanced Digital Features To view enhanced digital features for this article go to https://doi.org/10.6084/ m9.figshare.9577574.

M. L. Levy $(\bowtie)$

Sessional General Practitioner, Kenton Bridge

Medical Centre, London, UK

e-mail: marklevy@animalswild.com

W. Carroll

Department of Paediatrics, University Hospital of

North Midlands NHS Trust, Stoke-on-Trent, UK

J. L. Izquierdo Alonso

Service of Pneumology, Guadalajara University

Hospital, University of Alcalá, Madrid, Spain

C. Keller

Practice for Pneumology, Allergology and Work

Medicine, Frankfurt, Germany

F. Lavorini

Section of Respiratory Medicine, Department of Clinical and Experimental Medicine, University of Florence, Florence, Italy

\section{Lehtimäki}

Faculty of Medicine and Health Technology, Allergy Centre, Tampere University Hospital, Tampere University, Tampere, Finland valuable option for almost all of the patients with asthma or COPD. Based on recorded patient inspiratory profiles, the peak inspiratory flow requirement of $30 \mathrm{~L} \mathrm{~min}^{-1}$ of high-resistance devices does not usually pose any practical limitations for the patients. Suboptimal adherence and errors in device handling are common and require continuous checking and patient education in order to avoid these pitfalls of all inhalation therapy. The aim of this opinion paper is to describe the working principles of DPIs and to summarise their key properties in order to help prescribing the correct inhaler for each patient.

Funding: Orion Pharma.

Keywords: Adherence; Asthma; COPD; Device resistance; Dry powder inhalers; Respiratory

\section{DIFFERENT TYPES OF INHALERS}

The history of inhaler technology goes back almost 250 years. The first time the word inhaler was used was related to the 'Mudge' Inhaler in 1778 [1]. In modern inhalation therapy, there are four main device types. The first devices resembling nebulisers were introduced in the 1860s, metered dose inhalers (MDI) were developed in the 1950s, dry powder inhalers (DPI) in the 1980s and soft mist inhalers (SMI) after the year 2000 . 
In 2006, Chrystyn et al. [2] proposed five qualities which are required for an ideal inhaler'. Firstly, the emitted dose must have appropriate aerodynamic characteristics to be as much as possible independent of a patient's characteristics and clinical condition. Secondly, delivery of the drug must be safe and effective, thus maximising the therapeutic effects locally, while minimising systemic effects. Thirdly, the inhaler must be easy and intuitive to use. Fourthly, the device must be appealing to the patient to promote adherence and proper use. And lastly, ideally, a single device type should include all of the patient's required inhalable treatments.

Since 2006, there has been an increased recognition of global environmental threats. There has therefore been increasing pressure to include environmental factors in the ideal features. To limit the depletion of the ozone layer, the permitted level of chlorofluorocarbons (CFC) produced was reduced from $150 \%$ of calculated levels of production and consumption to zero between 1986 and 2010 by the Montreal Protocol [3]. In response to these changes, the pharmaceutical industry increased its focus on the development of dry powder inhalers [4]. While pressurised MDIs (pMDIs) remain the most commonly prescribed type of inhaler [5], even in the post-CFC era, they still pose an environmental hazard [6], as the modern propellants (hydrofluorocarbons and hydrofluoroalkanes) are roughly 1300 times more potent than $\mathrm{CO}_{2}$ as greenhouse gases. In fact, the carbon footprint of pMDIs has been reported to be over 100 -fold greater than that of DPIs [7].

The properties of each device type, including pros and cons, are outlined in Table 1: pMDIs facilitate patient-independent aerosolisation, but require sufficient coordination upon actuation; nebulisers allow delivery during normal breathing patterns, but are cumbersome to carry and need cleaning and servicing; SMIs are portable, but like pMDIs handling and co-ordination for dosing may be difficult for some subjects in comparison with DPIs; finally, DPIs are convenient and lightweight but rely upon patient inhalation technique to aerosolise the drug powder [8]. Taking environmental considerations into account, DPIs, being portable and easy to use, offer an appealing option for pulmonary drug delivery. Choosing the right device for the right patient is not as straightforward as it might first appear. Myths and misconceptions persist-particularly with DPIs-and debunking these will help clinicians pick the best device for their patient. For these reasons, this opinion paper aims to discuss the benefits and drawbacks of DPIs, from both a device and a patient's perspective.

This article is based on previously conducted studies and does not contain any studies with human participants or animals performed by any of the authors.

\section{FROM POWDER TO AEROSOL}

Despite their apparent simplicity, dry powder inhalers are sophisticated devices. In order to deliver active drug to the respiratory tract, the user must inhale through the device. This inhalation provides energy which breaks up the compacted drug powder, a process called deagglomeration, and transports this de-agglomerated drug into the lung [9]. Most DPIs contain a micronised drug blended with carrier particles such as lactose that prevent aggregation and provide sufficient flowability. To enhance the aerosolisation of the drug particles, fine lactose particles are often added to the carrier lactose to saturate high-energy binding sites on the carrier lactose and form easily detachable aggregates with the drug particles. Both mechanisms contribute to higher fine particle dose, which is defined as the dose able to penetrate deep into the lungs [10-13].

When the patient activates the DPI and inhales, airflow through the device creates shear forces and airflow turbulence. As the powder is emitted from the inhaler, the drug particles separate from the carrier particles and are carried deep into the lungs, while the larger carrier particles end up in the oropharynx and are swallowed/cleared [8]. Thus, the level of deposition into the lungs is determined by a combination of two factors: the patient's inspiratory effort and the device's properties (e.g. shape of the mouth piece, flow resistance and flow) [14] 


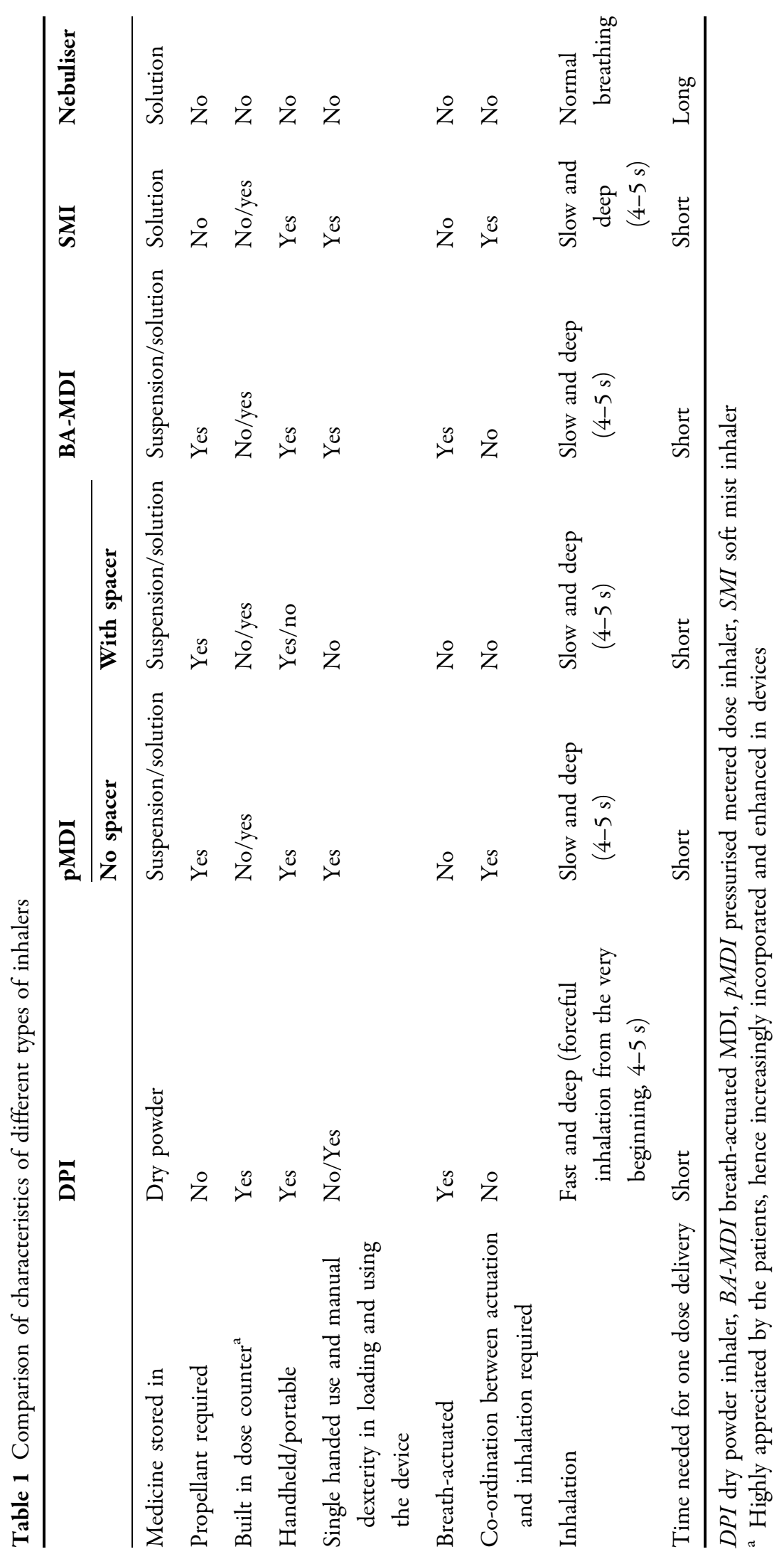


[15]. To achieve efficient aerosol dispersion, drug formulations have been developed in conjunction with varying DPI design elements, such as swirl chambers, grids and lacunas, to subsequently present varying degrees of airflow resistance. Hence, each DPI results in different pressure-drop and flow-rate characteristics. In general, the flow rate though a DPI is proportional to the square root of the pressure drop that the patient develops across it. The constant of proportionality is termed the device resistance [16].

Counterintuitively, higher resistance is often an advantage with DPIs. With the exception of the Turbuhaler (AstraZeneca), medium-to-highresistance inhalers require lower patient inspiratory flow rates for optimal performance (Fig. 1) [17-22]. Generally, higher-resistance devices generate more turbulent flow, more effectively converting the work done by the patient to energy available for de-agglomeration of the drug particles [23-25]. In contrast, the Turbuhaler uses a built-in cyclone to de-agglomerate the formulation, and therefore has a minimum threshold for inspiratory flow rate to effectively aerosolise the drug particles [26]. In breath-actuated DPI devices, a certain pre-determined threshold in inspiratory flow rate has to be achieved before the drug is released from the inhaler. This prevents drug release at low flow rates that would not be high enough to allow effective de-agglomeration and would therefore result in low pulmonary deposition. Devices at the lower end of the resistance spectrum use less manipulation of flow patterns through the inhaler, and therefore rely more on the patient generating a flow rate that achieves sufficient de-agglomeration. With these principles in mind, patients with impaired pulmonary function could benefit from devices with higher resistance [21].

European and US pharmacopoeia recommend the use of a standardised pressure drop of $4 \mathrm{kPa}$ for in vitro characterisation of DPI products. As this was originally intended as a method in quality control in the context of batch release, it is ill suited to produce data relevant to performance with patients. Recent publications are instead reporting the use of fixed ranges of inspiratory flow rates or patient population-specific percentiles when trying to simulate real-life conditions $[18,20,27]$. Haidl et al. [28] have suggested criteria for a successful inhalation manoeuvre, namely sufficient device-specific inhalation flow rate, flow acceleration, inhalation volume and inhaled volume after actuation. Based on this review, the peak inspiratory flow rate (PIF) of $30 \mathrm{~L} \mathrm{~min}^{-1}$ is sufficient for various DPIs of different operating principles, e.g. Easyhaler (reservoir; Orion),

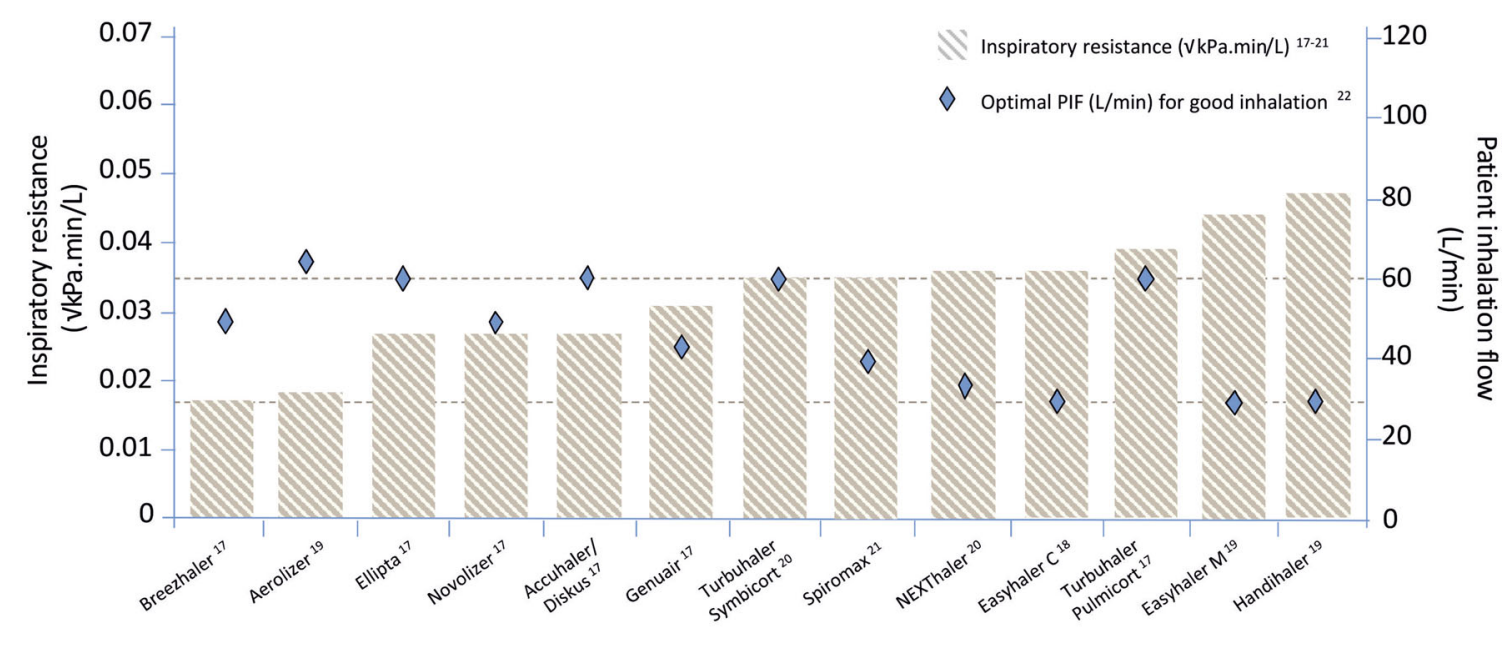

Abbreviations: Peak Inspiratory Flow (PIF); Easyhaler M = Easyhaler Monotherapy; Easyhaler C= Easyhaler Combination therapy. Optimal PIF refers to the lower limit of desired inspiratory flow

Fig. 1 Dry powder inhaler resistance and optimal peak inspiratory flow for adequate drug delivery 
Handihaler (capsule; Boehringer-Ingelheim) and Ellipta (blister; GlaxoSmithKline). Patients' inspiratory efforts have been shown to vary between age ranges (from paediatric to geriatric) and indications (from asthma to COPD) $[22,29,30]$. However, the expected PIF of 30 $\mathrm{L} \mathrm{min}^{-1}$ seems to be well within reasonable limits. For example, when PIF was studied on the Easyhaler (a relatively high-resistance device compared with the Symbicort Turbuhaler) in adult and paediatric patients with asthma, as well as adults with COPD, the 10th, 50th and 90th percentiles for PIF were $44.7 \mathrm{~L} \mathrm{~min}^{-1}, 61.1$ $\mathrm{L} \mathrm{min}^{-1}$ and $74.8 \mathrm{~L} \mathrm{~min}^{-1}$ [18], respectively. Further, the dosing has been shown to be consistent for PIF values of 28.3-74.8 $\mathrm{L} \mathrm{min}^{-1}$ [31, 32]. (Fig. 2).

\section{INHALER USE IN PRACTICE: PITFALLS AND SUCCESSES}

Drugs are only effective if they can reach their site of action. In pulmonary delivery, the inhaler adds an extra step and a further potential barrier. Clinicians working with patients will be only too aware that there are many possible ways to use an inhaler device incorrectly. Education is vital and continuous re-education is also required. Recently, this has been addressed by third parties (e.g. https://www.rightbreathe. com), who provide commercially independent training materials and educational videos on the use of inhalers, but more work is still needed. Melani et al. studied the user-associated mistakes made by 1664 adults with asthma and COPD who used MDIs and DPIs at home. The most common mistakes made with DPIs were exhaling into the inhaler before or after actuation and a lack of holding breath after the inhalation [33]. Sandler et al. showed that relatively few inhaler-naïve adults were able to use an inhaler [either the Spiromax (Teva), Easyhaler or Turbuhaler] correctly without training (just over a third), but following careful guidance by a healthcare provider (HCP), > 95\% can master the technical aspects required for successful inhalation [34]. Patient education is required at diagnosis, at regular intervals, and certainly if the inhaler device is changed. Continuous checking and coaching also promotes the HCP-patient partnership and the active involvement of the patient and reduces unscheduled health care utilisation in asthma
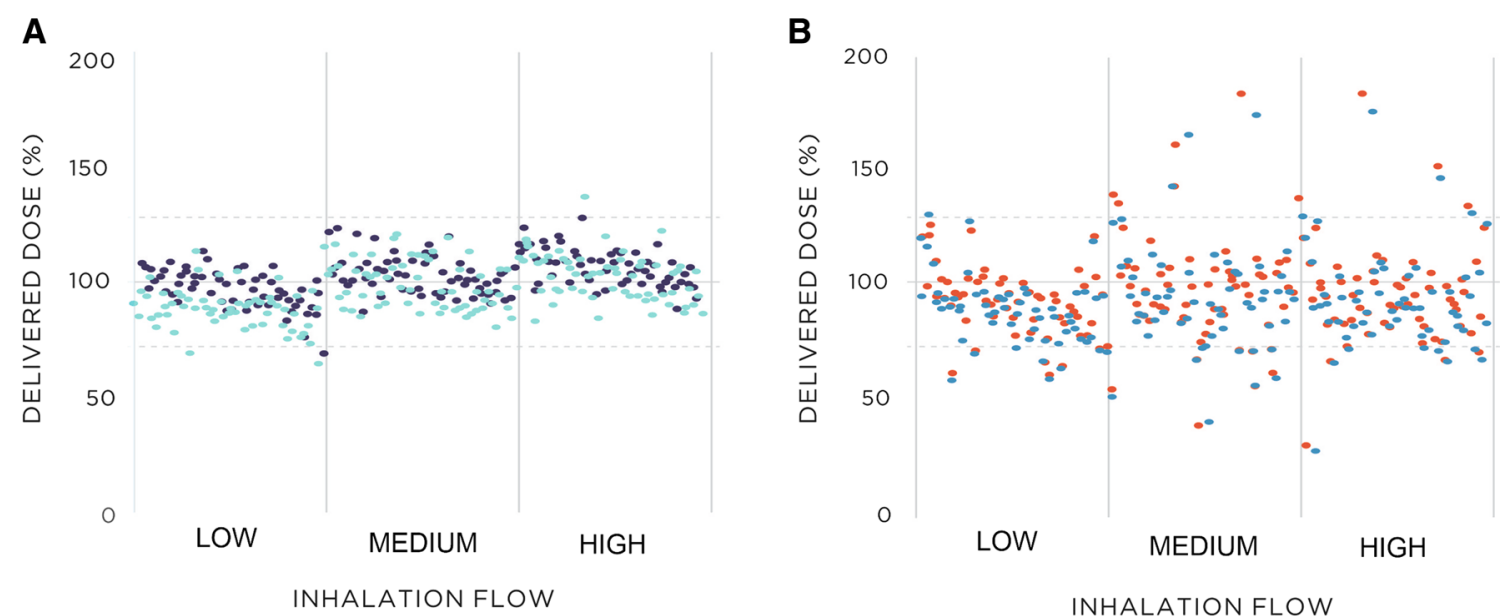

INHALATION FLOW

INHALATION FLOW

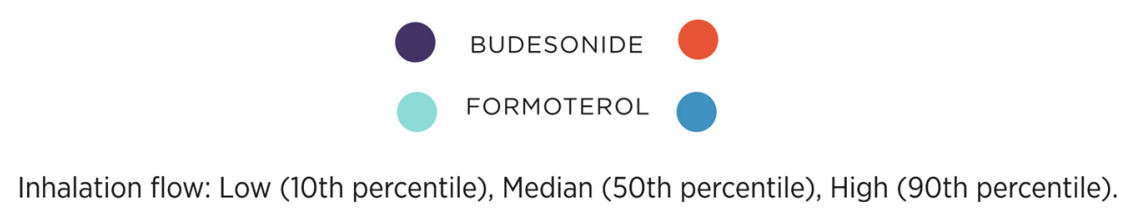

Fig. 2 Comparison of two budesonide/formoterol DPIs 160/4.5 $\mathrm{g}$ /dose, Easyhaler (a) and Turbuhaler (b) regarding the consistency of the delivered dose at different inhalation flow rates [31] 
and COPD $[35,36]$. Mistakes in the use of the inhaler have been shown to affect outcomes, but no conclusive evidence has been demonstrated using direct comparisons between inhaler types or devices [37-40]. Taking into account that inhaler use has not improved during the last 40 years, substantial effort is needed from both HCPs and inhaler designers to rectify this issue [41].

The range of different medications available for administration via inhalers is vast and may be a source of confusion, for HCPs and especially for lay people. Patients with asthma are often satisfied with their reliever, short-acting beta agonist (SABA)-only treatment, because of their quick onset of action and immediate relief of symptoms. This may lead patients to believe that their asthma is controlled by their reliever therapy; however regular SABA-use is associated with poor outcomes [42, 43]. Dispensing three or more canisters of SABA a year is associated with increased hospital attendance [44], and more than 12 a year with risk of asthma deaths, [45] even in patients with minimal symptoms $[46,47]$. This highlights the need to educate patients regarding the functions of the different drugs that they are prescribed. In the most recent 2019 Global Initiative for Asthma (GINA) report, a trend to simplify the treatment regimen can be seen [48]. The formerly used step 1 (SABA-only) treatment regimen was disregarded. Instead, with safety as the main priority, GINA now recommends that all patients with asthma should be prescribed inhaled steroids intermittently (in mild asthma) or continuously. GINA no longer recommends SABA as first-line treatment and recommends a combination of low-dose inhaled corticosteroids (ICS) and formoterol as needed in mild cases (less than 2 episodes of symptoms a month) and as an alternative to regular ICS in Step 2 of the GINA's stepwise asthma management approach. This treatment strategy has been shown to reduce serious exacerbations when compared with SABA-only and to be non-inferior when compared with daily ICS and SABA as needed $[49,50]$. Furthermore, a real-world comparison of as-needed ICS-formoterol in GINA's stepwise asthma management approach, Step 1 and 2 patients with as-needed albuterol (salbutamol) demonstrated significantly lower asthma exacerbations in the as-needed ICS-formoterol group [51]. As steps 1 and 2, according to the new GINA strategy, can now be managed with single combined treatment as needed it will simplify the treatment. It also makes use of the incorrect practices by patients with infrequent symptoms not using their regular medication [52] and their urge for reliever therapy to control their disease. Therefore, the new GINA report takes a step towards a Maintenance and Reliever Therapy (MART) regimen, in which control and reliever therapy is combined in a single product. The concept of simplifying the treatment regimen has previously been employed in other fields of medicine. For example, when treating hypertension and dyslipidemia, medication may be combined to a single tablet to increase patient adherence [53]. It is worth mentioning that the studies cited in the new GINA report were conducted only with budesonide-formoterol combination therapy, and the clinical data have been extrapolated to also include other ICS. The recommendations are currently off-label and specifically include lowdose ICS-formoterol preparations to take advantage of the rapid action of formoterol.

In a cost-benefit analysis by Haahtela et al., Finnish asthma-related healthcare costs decreased by $14 \%$ between 1987 and 2013 despite a 3 -fold increase in the number of diagnoses and an increase in medication costs [54]. As with the latest GINA guidelines, one of the cornerstones of the Finnish asthma program was to start inhaled corticosteroids as first-line treatment for all patients. The results from the program suggest that increased disease control not only improves patients' quality of life but also provides wider societal benefits (e.g. economic benefits and improvements in integrated care) [55].

When compared with other types of inhalers, DPIs have a markedly different risk profile concerning the ambient environment. While they resist microbiological contamination extremely well, they are often susceptible to changes in their physical composition. For example, changes in crystallinity or agglomeration due to moisture may result in decreased performance of the product [56]. When applying for marketing approval, all inhalers must have evidence that they work well if stored 
according to their summary of product characteristics. Therefore, patient training should not be constrained to the use of an inhaler, but should also include handling and storing of the device.

\section{INHALERS ARE FOR PATIENTS}

From the patient's perspective, the requirements for an ideal inhaler can be summarised with six E's (Fig. 3). An inhaler must be Effective; i.e. able to deliver the aerosols with particle sizes of respirable range and independent, as much as possible, of the inhalation volume and flow rate. This minimises the variation between patients, but also guarantees effective treatment when a single patient's clinical parameters vary during treatment. Successful delivery straight to the site of action also allows the drug to act with minimal adverse effects. An inhaler must also be Efficient, i.e. easy to handle and able to be used with relatively few handling steps; these properties contribute to compliance and error-free handling. An Engaging design promotes patient satisfaction and adherence, leading to better treatment outcomes. Despite all the training and efforts of the HCPs, patients will continue to make errors with their inhalers; therefore, a well-designed inhaler is Error-tolerant and will minimise the effects of at least the most common user errors. An inhaler should also be Easy-to-teach; when teaching the use of an inhaler is easy and fast, the HCP can check the

1. Effective: delivers particle sizes in the respirable range

2. Efficient: is easy and consistent to use

3. Engaging: is appreciated by patients

4. Error-tolerant: is robust in every-day use

5. Easy-to-teach: is easy to teach by HCPs, and easy to learn and use by patients

6. Easy-to-switch to: is easy and efficient to switch to, if so needed e.g. for cost-effectiveness reasons

Fig. 3 Six E's patient's inhaler technique more easily and retrain the patient in using their device. Improvements in patients' technical proficiency are likely to result in better treatment outcomes as the doses are more consistently delivered to the site of action. Chronic diseases as asthma and COPD are not only problematic for patients themselves, but provide a considerable societal burden; therefore, an ideal inhaler is also Easy-to-switch to when needed (e.g. at the population level, for cost-effectiveness reasons).

Patients of all ages have been reported to be particularly poorly adherent to inhaled medication $[57,58]$. To address this problem, many companies have developed web-based information platforms (e.g. https://www.wehale.life/ [Orion pharma] and https://www.asthma.com/ ;Glaxo-Smith Kline) and inhaler-mounted smart devices, to give advice and feedback to the patient. Current guidelines on asthma and COPD promote the active involvement of the patient when choosing the inhaler. Satisfaction with an inhaler has been shown to relate to adherence and asthma control [59]. Differences in satisfaction between inhalers have been reported to arise from convenience-related factors such as portability, weight and size, and from usability factors such as preparation and use [60]. Several studies have reported therapeutic equivalence and successful switches between the inhalers (e.g. from Turbuhaler to Aerolizer, Spiromax, Easyhaler and Novolizer) [61-64]. An example of a large scale switch in real-life practice comes from Norway, where the health authority (Statens legemiddelverk) included the Bufomix Easyhaler and Duoresp Spiromax in its switch regimen of DPIs containing budesonide/formoterol in Norwegian pharmacies, starting on July 1, 2018 [65].

\section{CONCLUSIONS}

In the market, there are many devices which are capable of delivering the drugs to the lungs of the patient. The myriad of devices and complex physics involved in the delivery makes it difficult for clinicians to choose the right device for their patients. For the majority of patients, 
there is a sufficiently effective combination of drug molecules available for use. However, poor adherence and incompetence with the device remain as frequent problems in inhalation therapy. Most patients are able to use nebulisers and pMDIs as well as high- and low-resistance DPIs. There is rarely a single best device for any given patient, and the choice should be made with the patient to take into account the parameters which are important to the actual user, such as size, portability or environmental factors. These properties valued by the patients may be medically irrelevant but through adherence could be the defining factor in the success of the treatment.

\section{ACKNOWLEDGEMENTS}

Funding. Funding for this study, the Rapid Service Fee, and the open access charge was provided by Orion Pharma, Orion Corporation.

Medical Writing and Editorial Assistance. Writing and editing assistance, including preparation of a draft manuscript under the direction and guidance of the authors, incorporation of author feedback, and manuscript submission, was provided by Dr. David Griffiths (Bioscript, UK), and Ville Vartiainen, MD, PhD, MSc (Orion Pharma, Orion Corporation, Finland).

Authorship. All named authors meet the International Committee of Medical Journal Editors (ICMJE) criteria for authorship for this article, had full access to the articles reviewed in this manuscript, take complete responsibility for the integrity and accuracy of the work as a whole, and have given their approval for this version to be published.

Disclosures. Mark L. Levy reports personal fees from Clement Clarke International, Teva, AstraZeneca, Chiesi, Conzorcio Futuro In Ricerca, Soar Beyond, Orion Pharma, Napp Pharmaceuticals, National Services for Health
Improvement, Novartis Pharmaceuticals, Trudel Pharmaceuticals and GlaxoSmithKlein. He has had non-financial support from the Global Initiative on Asthma (GINA), and from Whole Systems Integrated Care (WSIC) North West London outside the submitted work. He was the clinical Lead for the UK National Review of Asthma Deaths (2011-2014). Will Carroll has received speaker fees and honoraria for advisory board work from GlaxoSmithKline, Novartis, Orion Pharma and Trudell Medical International. José L. Izquierdo Alonso has received honoraria for speaking engagements and consultancy fees from AstraZeneca, Bayer, Boehringer-Ingelheim, Chiesi, GlaxoSmithKline, Menarini, Novartis, Orion Pharma, Pfizer, Sandoz and Teva. Claus Keller has received a speaker honorarium from AstraZeneca, Berlin Chemie, GlaxoSmithKline and Boehringer Ingelheim. Federico Lavorini has received grants for reasearch or fees for speaking and advisory boards from AstraZeneca, Boehirnger Ingelheim, Chiesi, GlaxoSmithKline, Menarini International, Novartis, Orion Pharma, and Trudell Medical International. Lauri Lehtimäki has received honoraria from AstraZeneca, Boehringer-Ingelheim, Chiesi, GSK, Novartis, Mundipharma, Orion Pharma, Sanofi and Teva.

Compliance with Ethics Guidelines. This article does not contain any studies with human participants or animals performed by any of the authors.

Data Availability. Data sharing is not applicable to this article as no data sets were generated or analyzed during the current study.

Open Access. This article is distributed under the terms of the Creative Commons Attribution-NonCommercial 4.0 International License (http://creativecommons.org/licenses/ by-nc/4.0/), which permits any noncommercial use, distribution, and reproduction in any medium, provided you give appropriate credit to the original author(s) and the source, provide a link to the Creative Commons license, and indicate if changes were made. 


\section{REFERENCES}

1. Sanders M. Inhalation therapy: an historical review. Prim Care Respir J. 2007;16:71-81.

2. Chrystyn H. Closer to an "ideal inhaler" with the Easyhaler: an innovative dry powder inhaler. Clin Drug Investig. 2006;26:175-83.

3. UN Environment (UNEP). Handbook for the montreal protocol on substances that deplete the ozone layer, 10th edn. 2016. https://observatoriop10. cepal.org/sites/default/files/documents/treaties/mphandbook-2016-english.pdf. Accessed 27 Aug 2019.

4. Crompton GK. Dry powder inhalers: advantages and limitations. J Aerosol Med. 1991;4:151-6.

5. Lavorini F, Corrigan CJ, Barnes PJ, Dekhuijzen PRN, Levy ML, Pedersen S, et al. Retail sales of inhalation devices in European countries: so much for a global policy. Respir Med. 2011;105:1099-103.

6. Sellers WFS. Asthma pressurised metered dose inhaler performance: propellant effect studies in delivery systems. Allergy, Asthma Clin Immunol. 2017;13:30.

7. UN Environment (UNEP). Handbook for the montreal protocol on substances that deplete the ozone layer, 12th edn. 2018. https://ozone.unep.org/sites/ default/files/MP_handbook-english-2018.pdf. Accessed 22 July 2019.

8. Laube BL, Janssens HM, de Jongh FHC, Devadason SG, Dhand R, Diot P, et al. What the pulmonary specialist should know about the new inhalation therapies. Eur Respir J. 2011;37:1308-417.

9. Frijlink HW, De Boer AH. Dry powder inhalers for pulmonary drug delivery. Expert Opin Drug Deliv. 2004;1:67-86.

10. Kinnunen H, Hebbink G, Peters H, Shur J, Price R. An investigation into the effect of fine lactose particles on the fluidization behaviour and aerosolization performance of carrier-based dry powder inhaler formulations. AAPS PharmSciTech. 2014;15:898-909.

11. Ho R, Muresan AS, Hebbink GA, Heng JYY. Influence of fines on the surface energy heterogeneity of lactose for pulmonary drug delivery. Int J Pharm. 2010;388:88-94.

12. Zeng XM, Martin GP, Tee SK, Ghoush AA, Marriott C. Effects of particle size and adding sequence of fine lactose on the deposition of salbutamol sulphate from a dry powder formulation. Int J Pharm. $1999 ; 182: 133-44$.
13. Adi H, Larson I, Chiou H, Young P, Traini D, Stewart P. Role of Agglomeration in the Dispersion of Salmeterol Xinafoate from Mixtures for Inhalation with Differing Drug to Fine Lactose Ratios. J Pharm Sci. 2008;97:3140-52.

14. Telko MJ, Hickey AJ. Dry powder inhaler formulation. Respir Care. 2005;50:1209-27.

15. Weers J, Clark A. The Impact of Inspiratory Flow Rate on Drug Delivery to the Lungs with Dry Powder Inhalers. Pharm Res. United States. 2017;34:507-28.

16. Azouz W, Chrystyn H. Clarifying the dilemmas about inhalation techniques for dry powder inhalers: integrating science with clinical practice. Prim Care Respir J. 2012;21:208-13.

17. Krüger P, Ehrlein B, Zier M, Greguletz R. Inspiratory flow resistance of marketed dry powder inhalers (DPI). Eur Respir J [Internet]. 2014;44:4635. http:// erj.ersjournals.com/content/44/Suppl_58/4635.abst ract. Accessed 22 July 2019.

18. Malmberg LP, Everard ML, Haikarainen J, Lähelmä S. Evaluation of in vitro and in vivo flow rate dependency of budesonide/formoterol Easyhaler ${ }^{\circledR}$. J Aerosol Med Pulm Drug Deliv. 2014;27:329-40.

19. Delvadia R, Hindle M, Longest PW, Byron PR. In vitro tests for aerosol deposition II: IVIVCs for different dry powder inhalers in normal adults. J Aerosol Med Pulm Drug Deliv. 2013;26:138-44.

20. Buttini F, Brambilla G, Copelli D, Sisti V, Balducci AG, Bettini R, et al. Effect of flow rate on in vitro aerodynamic performance of NEXThaler ${ }^{\circledR}$ in comparison with diskus ${ }^{\circledR}$ and Turbohaler ${ }^{\circledR}$ dry powder inhalers. J Aerosol Med Pulm Drug Deliv. 2016;29:167-78.

21. Pohlmann G, Hohlfeld JM, Haidl P, Pankalla J, Cloes RM. Assessment of the power required for optimal use of current inhalation devices. J Aerosol Med Pulm Drug Deliv [Internet]. 2018;31:339-46. https://doi.org/10.1089/jamp.2017.1376.

22. Ghosh S, Ohar JA, Drummond MB. Peak Inspiratory Flow Rate in Chronic Obstructive Pulmonary Disease: implications for Dry Powder Inhalers. J Aerosol Med Pulm Drug Deliv. 2017;30:381-7.

23. Voss A, Finlay WH. Deagglomeration of dry powder pharmaceutical aerosols. Int J Pharm. 2002;248: $39-50$

24. Mäkelä M, Chrystyn H, Lavorini F, Canonica GW. Back to Basics in Asthma and COPD: optimising the Patient Journey. Eur Med J Respir. 2018;6:47-54. 
25. Clark AR, Hollingworth AM. The relationship between powder inhaler resistance and peak inspiratory conditions in healthy volunteers-implications for in vitro testing. J Aerosol Med. 1993;6:99-110.

26. Palander A, Mattila T, Karhu M, Muttonen E. In vitro Comparison of Three Salbutamol-Containing Multidose Dry Powder Inhalers. Clin Drug Investig. 2000;20:25-33.

27. Jõgi R, Lähelmä S, Vahteristo $M$, Happonen A, Haikarainen J. In vitro flow rate dependency of delivered dose and fine particle dose of salmeterol/ fluticasone propionate easyhaler and seretide diskus with patient flow rates collected in a randomized controlled trial. J Aerosol Med Pulm Drug Deliv. 2018;31:jamp.2018.1463.

28. Haidl P, Heindl S, Siemon K, Bernacka M, Cloes RM. Inhalation device requirements for patients' inhalation maneuvers. Respir Med. 2016;118:6575.

29. Azouz W, Chetcuti P, Hosker HSR, Saralaya D, Stephenson J, Chrystyn H. The inhalation characteristics of patients when they use different dry powder inhalers. J Aerosol Med Pulm Drug Deliv. 2015;28:35-42.

30. Malmberg LP, Rytilä P, Happonen P, Haahtela T. Inspiratory flows through dry powder inhaler in chronic obstructive pulmonary disease: age and gender rather than severity matters. Int $\mathrm{J}$ Chron Obstruct Pulmon Dis. 2010;5:257-62.

31. Haikarainen J, Selroos O, Löytänä T, Metsärinne S, Happonen A, Rytilä P. Budesonide/Formoterol Easyhaler $^{\circledR}$ : performance under simulated real-life conditions. Pulm Ther. 2017;3:125-38.

32. Abadelah M, Hazim F, Chrystyn H, Bagherisadeghi G, Rahmoune H, Larhrib $H$. Effect of maximum inhalation flow and inhaled volume on formoterol drug deposition in vitro from an Easyhaler $^{\circledR}$ dry powder inhaler. Eur J Pharm Sci. 2017;104:180-7.

33. Melani AS, Bonavia M, Cilenti V, Cinti C, Lodi M, Martucci $\mathrm{P}$, et al. Inhaler mishandling remains common in real life and is associated with reduced disease control. Respir Med. 2011;105:930-8.

34. Sandler N, Holländer J, Långström D, Santtila P, Saukkonen A, Torvinen S. Evaluation of inhaler handling-errors, inhaler perception and preference with Spiromax, Easyhaler and Turbuhaler devices among healthy Finnish volunteers: a single site, single visit crossover study (Finhaler). BMJ Open Respir Res. 2016;3(1):e00119.

35. Takemura M, Kobayashi M, Kimura K, Mitsui K, Masui H, Koyama M, et al. Repeated instruction on inhalation technique improves adherence to the therapeutic regimen in asthma. J Asthma. 2010;47:202-8.

36. Takemura M, Mitsui K, Itotani R, Ishitoko M, Suzuki $\mathrm{S}$, Matsumoto $\mathrm{M}$, et al. Relationships between repeated instruction on inhalation therapy, medication adherence, and health status in chronic obstructive pulmonary disease. Int $\mathrm{J}$ Chron Obstruct Pulmon Dis. 2011;6:97-104.

37. Price DB, Román-Rodríguez M, McQueen RB, Bosnic-Anticevich S, Carter V, Gruffydd-Jones K, et al. Inhaler Errors in the CRITIKAL Study: type, frequency, and association with asthma outcomes. J Allergy Clin Immunol Pract. 2017;5:1071-81.e9.

38. Price D, Bosnic-Anticevich S, Briggs A, Chrystyn H, Rand C, Inhaler Error Steering Committee, et al. Inhaler competence in asthma: common errors, barriers to use and recommended solutions. Respir Med. 2013;107:37-46.

39. Chrystyn H, van der Palen J, Sharma R, Barnes N, Delafont B, Mahajan A, et al. Device errors in asthma and COPD: systematic literature review and meta-analysis. NPJ Prim care Respir Med. 2017;27: 22.

40. Lavorini F, Magnan A, Dubus JC, Voshaar T, Corbetta $\mathrm{L}$, Broeders $\mathrm{M}$, et al. Effect of incorrect use of dry powder inhalers on management of patients with asthma and COPD. Respir Med. 2008;102: 593-604.

41. Sanchis J, Gich I, Pedersen S, Aerosol Drug Management Improvement Team (ADMIT). Systematic review of errors in inhaler use: has patient technique improved over time? Chest. 2016;150: 394-406.

42. Hancox RJ, Cowan JO, Flannery EM, Herbison GP, McLachlan CR, Taylor DR. Bronchodilator tolerance and rebound bronchoconstriction during regular inhaled beta-agonist treatment. Respir Med. 2000;94:767-71.

43. Aldridge RE, Hancox RJ, Robin Taylor D, Cowan JO, Winn MC, Frampton CM, et al. Effects of terbutaline and budesonide on sputum cells and bronchial hyperresponsiveness in asthma. Am J Respir Crit Care Med. 2000;161:1459-64.

44. Stanford RH, Shah MB, D'Souza AO, Dhamane AD, Schatz M. Short-acting beta-agonist use and its ability to predict future asthma-related outcomes. Ann Allergy Asthma Immunol. 2012;109:403-7.

45. Suissa S, Ernst P, Boivin JF, Horwitz RI, Habbick B, Cockroft D, et al. A cohort analysis of excess mortality in asthma and the use of inhaled beta-agonists. Am J Respir Crit Care Med. 1994;149:604-10. 
46. Reddel HK, Ampon RD, Sawyer SM, Peters MJ. Risks associated with managing asthma without a preventer: urgent healthcare, poor asthma control and over-the- counter reliever use in a cross-sectional population survey. BMJ Open. 2017. https://doi. org/10.1136/bmjopen-2017-016688.

47. Dusser D, Montani D, Chanez P, de Blic J, Delacourt C, Deschildre A, et al. Mild asthma: an expert review on epidemiology, clinical characteristics and treatment recommendations. Allergy. 2007;62:591-604.

48. Global strategy for asthma management and prevention. Global Initiative for Asthma (GINA), 2019 [Internet]. https://ginasthma.org/wp-content/uploa ds/2019/06/GINA-2019-main-report-June-2019-wms. pdf. Accessed 13 Jul 2019.

49. O'Byrne PM, FitzGerald JM, Bateman ED, Barnes PJ, Zhong N, Keen C, Jorup C, Lamarca R, Ivanov S, Reddel HK. Inhaled combined budesonide-formoterol as needed in mild asthma. New Engl J Med. 2018;378(20):1865-76.

50. Bateman E, Reddel H, O'Byrne P, Barnes P, Zhong $\mathrm{N}$, Keen $\mathrm{C}$, et al. As-needed budesonide-formoterol versus maintenance budesonide in mild asthma. N Engl J Med. 2018;378:1877-87.

51. Beasley R, Holliday M, Reddel HK, Braithwaite I, Ebmeier S, Hancox RJ, et al. Controlled trial of budesonide-formoterol as needed for mild asthma. N Engl J Med. 2019;380:2020-30.

52. Price D, Fletcher M, van der Molen T. Asthma control and management in 8,000 European patients: the REcognise Asthma and LInk to Symptoms and Experience (REALISE) survey. NPJ Prim care Respir Med. 2014;24:14009.

53. Schulz M, Krueger K, Schuessel K, Friedland K, Laufs U, Mueller WE, et al. Medication adherence and persistence according to different antihypertensive drug classes: a retrospective cohort study of 255,500 patients. Int J Cardiol. 2016;220: 668-76.

54. Haahtela T, Herse F, Karjalainen J, Klaukka T, Linna M, Leskelä R-L, et al. The Finnish experience to save asthma costs by improving care in 1987-2013. J Allergy Clin Immunol. 2017;139(408-414):e2.

55. Burki TK. Asthma control: learning from Finland's success. Lancet Respir Med. 2019;7:207-8.
56. Janson C, Lööf T, Telg G, Stratelis G, Nilsson F. Difference in resistance to humidity between commonly used dry powder inhalers: an in vitro study. NPJ Prim Care Respir Med. 2016;26:16053.

57. Sulaiman I, Cushen B, Greene G, Seheult J, Seow D, Rawat F, et al. Objective assessment of adherence to inhalers by patients with chronic obstructive pulmonary disease. Am J Respir Crit Care Med. 2017;195:1333-43.

58. Papi A, Ryan D, Soriano JB, Chrystyn H, Bjermer L, Rodriguez-Roisin $\mathrm{R}$, et al. Relationship of inhaled corticosteroid adherence to asthma exacerbations in patients with moderate-to-severe asthma. J Allergy Clin Immunol Pract. 2018;6:1989-1998.e3.

59. Plaza V, Giner J, Calle M, Rytilä P, Campo C, Ribó P, et al. Impact of patient satisfaction with his or her inhaler on adherence and asthma control. Allergy Asthma Proc. 2018;39:437-45.

60. Valero A, Ribó P, Maíz L, Barbero E, Calle M, Campo $\mathrm{C}$, et al. Asthma patient satisfaction with different dry powder inhalers. Expert Rev Respir Med. 2019;13:133-8.

61. Lötvall J, Mellén A, Arvidsson P, Palmqvist M, Radielovic P, Kottakis J, et al. Similar bronchodilation with formoterol delivered by aerolizer or turbuhaler. Can Respir J. 1999;6:412-6.

62. Virchow JC, Rodriguez-Roisin R, Papi A, Shah TP, Gopalan G. A randomized, double-blinded, doubledummy efficacy and safety study of budesonide-formoterol Spiromax ${ }^{\circledR}$ compared to budesonide-formoterol Turbuhaler ${ }^{\circledR}$ in adults and adolescents with persistent asthma. BMC Pulm Med. 2016;16:42.

63. Zetterström O, Lähelmä S, Keski-Karhu J, Silvasti M, Östling-Kulling E, Ahonen A. Salbutamol via Easyhaler ${ }^{\circledR}$ is at least as effective as salbutamol via Turbuhaler ${ }^{\circledR}$ in the treatment of histamine-induced bronchoconstriction. Respir Med. 2000;94:1097-102.

64. Chuchalin AG, Kremer H-J, Metzenauer P, O'Keefe E, Hermann R. Clinical equivalence trial on budesonide delivered either by the novolizer ${ }^{\circledR}$ multidose dry powder inhaler or the turbuhaler ${ }^{\circledR}$ in asthmatic patients. Respiration. 2002;69:502-8.

65. Statens legemiddelverk. Inhalasjonpulver på byttelisten - vedtak gyldig. 2018. 